\title{
Burden of kidney failure from atheroembolic disease and association with survival in people receiving dialysis in Australia and New Zealand: a multi-centre registry study
}

Tahira Scott ${ }^{1,2^{*}}$, Isabelle Ethier ${ }^{1,3}$, Carmel Hawley ${ }^{1,4,5,6}$, Elaine M. Pascoe ${ }^{2,4}$, Andrea K. Viecelli ${ }^{1,5}$, Arnold Ng $^{7}$, Yeoungjee Cho ${ }^{1,4,5}$ and David W. Johnson ${ }^{1,4,5,6}$

\begin{abstract}
Background: Cardiovascular disease is a leading cause of mortality in kidney failure (KF). Patients with KF from atheroembolic disease are at higher risk of cardiovascular disease than other causes of KF. This study aimed to determine survival on dialysis for patients with KF from atheroembolic disease compared with other causes of KF.

Methods: All adults ( $\geq 18$ years) with KF initiating dialysis as the first kidney replacement therapy between 1 January 1990 and 31 December 2017 according to the Australia and New Zealand Dialysis and Transplant registry were included. Patients were grouped into either: KF from atheroembolic disease and all other causes of KF. Survival outcomes were assessed by the Kaplan-Meier method and Cox regression analysis adjusted for patient-related characteristics.

Results: Among 65,266 people on dialysis during the study period, 334 (0.5\%) patients had KF from atheroembolic disease. A decreasing annual incidence of KF from atheroembolic disease was observed from 2008 onwards. Individuals with KF from atheroembolic disease demonstrated worse survival on dialysis compared to those with other causes of KF (HR 1.80, 95\% confidence interval [CI] 1.61-2.03). The respective one- and five-year survival rates were 77 and $23 \%$ for KF from atheroembolic disease and 88 and $47 \%$ for other causes of KF. After adjustment for patient characteristics, KF from atheroembolic disease was not associated with increased patient mortality (adjusted $\mathrm{HR} 0.9395 \% \mathrm{Cl}$ 0.82-1.05).
\end{abstract}

Conclusions: Survival outcomes on dialysis are worse for individuals with KF from atheroembolic disease compared to those with other causes of KF, probably due to patient demographics and higher comorbidity.

Keywords: Atheroembolic disease, Dialysis, Kidney failure, Outcome, Registry, Survival

*Correspondence: Tahira.scott@health.qld.gov.au

1 Department of Nephrology, Level 2, ARTS Building, Princess Alexandra

Hospital, 199 Ipswich Road, Woolloongabba, Brisbane, QLD 4102,

Australia

Full list of author information is available at the end of the article

\section{Introduction}

Patients with kidney failure (KF) experience a higher mortality rate compared to the general population across all age groups. A leading cause of morbidity and mortality while on dialysis is atherosclerotic cardiovascular disease, contributing up to $50 \%$ of all-cause mortality [1]. Atherosclerotic cardiovascular disease also predisposes to an increased incidence of KF from

(c) The Author(s) 2021. Open Access This article is licensed under a Creative Commons Attribution 4.0 International License, which permits use, sharing, adaptation, distribution and reproduction in any medium or format, as long as you give appropriate credit to the original author(s) and the source, provide a link to the Creative Commons licence, and indicate if changes were made. The images or other third party material in this article are included in the article's Creative Commons licence, unless indicated otherwise in a credit line to the material. If material is not included in the article's Creative Commons licence and your intended use is not permitted by statutory regulation or exceeds the permitted use, you will need to obtain permission directly from the copyright holder. To view a copy of this licence, visit http://creativecommons.org/licenses/by/4.0/. The Creative Commons Public Domain Dedication waiver (http://creativeco mmons.org/publicdomain/zero/1.0/) applies to the data made available in this article, unless otherwise stated in a credit line to the data. 
atheroembolic disease of the kidney. Atheroembolic disease is a multisystem entity, whose aetiology is often iatrogenic after cardiac surgery, angiography, anticoagulation and thrombolysis but can occur spontaneously [2]. These precipitating events lead to the dislodgment of cholesterol emboli from the aorta to the kidney vasculature, leading to ischemia and KF [3].

The incidence of KF from atheroembolic disease is unknown but the prevalence is thought to be $1 \%[4$, 5]. There is limited data published on the morbidity and mortality of patients with KF from atheroembolic disease on dialysis. Several cohort studies suggest that clinical outcomes are worse for atheroembolic kidney disease than for other forms of kidney disease, including high rates of acute dialysis (28-61\%) [6-8], maintenance dialysis $(25-35 \%)[6,7]$ and one-year mortality (64-87\%) [3]. There are also no previous studies to our knowledge, that outlines the rate of transplantation in those with KF from atheroembolic disease.

This study aimed to evaluate patient survival on dialysis, kidney function recovery and rate of kidney transplantation in those with KF from atheroembolic disease compared with other forms of KF in the Australian and New Zealand populations, using data from the Australia and New Zealand Dialysis and Transplant (ANZDATA) registry.

\section{Material and methods}

Patient population

All incident adults ( $\geq 18$ years) with KF enrolled in the ANZDATA registry who commenced kidney replacement therapy (KRT) between 15 May 1963 and 31 December 2017 were considered for inclusion. A contemporary cohort of patients commencing KRT between 1 January 1990 and 31 December 2017, consisting of only patients who started KRT with dialysis was included for the final analysis, as there were only four cases of KF from atheroembolic disease before 1990.

Patients were categorised into two groups according to the cause of their primary kidney disease (atheroembolic disease and all other causes of KF), as recorded in the ANZDATA registry. The cause of KF was determined by each patient's primary nephrologist based on clinical picture, laboratory investigations and kidney biopsy, if available. This study used de-identified data from the ANZDATA registry with permission granted by the ANZDATA Executive. Ethical approval for the use of registry data was obtained from the Princess Alexandra Hospital Human Research Ethics Committee (LNR/2019/ QMS/50454). The study was conducted in accordance with STROBE guidelines [9].

\section{Study outcomes}

The primary outcome of this study was patient survival on dialysis, defined as death on dialysis (censored for kidney function recovery, loss to follow-up, kidney transplantation and end of study). Secondary outcomes examined were the annual proportion of KF attributed to atheroembolic disease, patient characteristics associated with KF from atheroembolic disease and recovery of kidney function defined as completion of dialysis therapy documented by the treating nephrologist. The onset of recovery was defined as the date of the last dialysis treatment.

\section{Statistical analysis}

Patient characteristics were expressed as frequency and percentages for categorical variables and median (interquartile range) for non-normally distributed continuous variables. Chi-squared (for categorical variables) and Wilcoxon sign rank test (for non-normally distributed continuous variables) tests were used to assess differences between cohorts.

Time-to-event analyses of patients with KF from atheroembolic disease versus all other KF causes were evaluated by Kaplan-Meier survival analysis using the log-rank test. Univariable and multivariable Cox proportional hazard survival analyses were completed with the covariates of disease group (atheroembolic vs all other KF), age, sex, ethnicity (Caucasian vs other), sub-era (1990-1998, 1999-2007 and 2008-2017), kidney replacement treatment (KRT) modality, late referral (defined as commencement of dialysis within 3 months of referral to a nephrologist), smoking status (current vs never/former), body mass index, comorbidities (diabetes mellitus, coronary artery disease, peripheral vascular disease, chronic lung disease and cerebrovascular disease) and country (Australia vs New Zealand). The proportionality assumption was examined visually with log-log survival plots. There were no significant first-order interactions identified. As a sensitivity analysis, a propensity score was generated using multivariable logistic regression including covariates in the multivariable Cox model to conduct 1:3 matched analysis (matched using nearest neighbor, no replacement approach). Statistical analysis was performed by Stata/IC version 16.1 (StataCorp, College Station, TX) software packages. $P$ values $<0.05$ were considered statistically significant.

\section{Results \\ Patient characteristics}

Between January 1990 and December 2017, 65,266 patients started dialysis, including 334 (0.5\%) patients with atheroembolic disease as the cause of KF (Fig. 1). 
81,890 KF from May 1965 -

December 2017

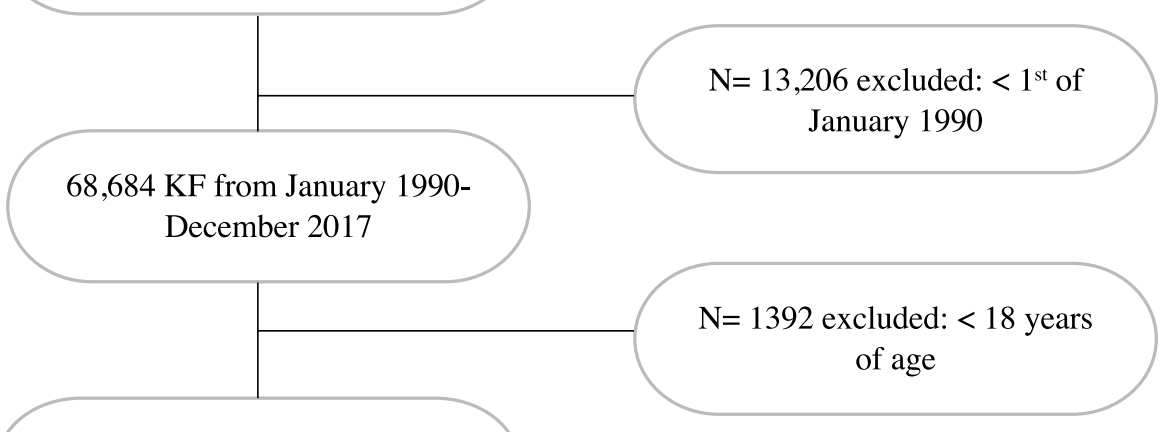

$67,292 \mathrm{KF} \geq 18$ years of age

$\mathrm{N}=2026$ excluded: pre-emptive transplant

65,266 included patients

Fig. 1 Study flow diagram. KF=kidney failure

The baseline characteristics are displayed in Table 1 . Patients with KF from atheroembolic disease were older at the commencement of KRT (72 vs 61 years), predominantly male ( $81 \%$ vs $60 \%$ ), Caucasian ( $96 \%$ vs $70 \%)$, referred late (51\% vs $21 \%$ ) and more likely to have coronary artery disease ( $80 \%$ vs $31 \%$ ), peripheral vascular disease (59\% vs $18 \%)$, chronic lung disease $(23 \%$ vs $12 \%)$ and cerebrovascular disease ( $32 \%$ vs $11 \%$ ). Missing data were less than $5 \%$ for all variables except for late referral (6\%) and kidney biopsy status (8.6\%; Table 1$)$.

\section{The burden of Atheroembolic disease}

The incidence of KF from atheroembolic disease was low compared to other causes of KF including those attributable to renovascular disease $(n=472,0.7 \%)$ and hypertension ( $n=8673,13 \%)$. The burden of KF from atheroembolic disease was highest from 1999 to 2007, representing $52 \%$ of the cases, and decreased substantially from 2008 to 2017 (Table 1 and Fig. 2).

\section{Patient survival on Dialysis}

During the study period, there were 34,571 deaths, with $283(0.8 \%)$ among those with KF from atheroembolic disease (1037 years at risk) and 34,288 (99.2\%) from KF from other causes (mortality incidence rate of 272.7 per 1000 person-years for KF from atheroembolic disease vs 152 per 1000 person-years for KF from other causes).
The median survival of those with KF from atheroembolic disease (2.87 years, 95\% confidence interval [CI] 2.53-3.36) was shorter than for KF from all other causes (4.67 years, 95\% CI 4.61-4.72). Respective survival rates after starting KRT were $77 \%$ versus $88 \%$ at 1 year and $23 \%$ versus $47 \%$ at 5 years. The causes of death on dialysis were comparable between the two groups. Cardiac death was the most common (35\% vs. $37 \%$ ), followed by dialysis withdrawal (32\% vs $29 \%)$, infection ( $11.5 \%$ vs $11.5 \%)$, vascular (10\% vs $8.6 \%)$ and other (12\% vs $13 \%)$.

In univariable Cox proportional hazard model analysis, KF from atheroembolic disease was associated with an increased risk of death (Fig. 3) (hazard ratio [HR] 1.80, 95\% CI 1.61-2.03). However, after adjustment for patient characteristics, this association was no longer observed (adjusted HR [aHR] 0.93, 95\% CI 0.82-1.05). In the multivariable model, the risk of mortality remained significant for age per decade (aHR 1.43, 95\% CI 1.42-1.45), $\mathrm{BMI}<18.5 \mathrm{~kg} / \mathrm{m}^{2}$ (aHR 1.43, 95\% CI 1.35-1.52), late referral (aHR 1.23, 95\% CI 1.20-1.26), diabetes mellitus (aHR 1.46, 95\% CI 1.43-1.50), coronary artery disease (aHR 1.30, 95\% CI 1.28-1.34), peripheral vascular disease (aHR 1.32, 95\% CI 1.28-1.35), chronic lung disease (aHR $1.30,95 \%$ CI 1.26-1.34), cerebrovascular disease (aHR 1.20 , 95\% CI 1.17-1.24), current smoking (aHR 1.26, 95\% CI 1.22-1.30), peritoneal dialysis (aHR 1.03, 95\% CI 1.01-1.06), dialysis era 1990-1998 (aHR 1.30, 95\% 
Table 1 Baseline patient characteristics of the complete cohorts

\begin{tabular}{|c|c|c|c|c|}
\hline Characteristics & All KF & $\begin{array}{l}\text { KF from atheroembolic } \\
\text { disease }\end{array}$ & KF all other causes & $P$-value \\
\hline$N=$ & 65,266 & 334 & 64,932 & \\
\hline Age at cohort entry (years) & $59(49-71)$ & $72(68-76)$ & $61(49-71)$ & $<0.001$ \\
\hline Male sex & $39,235(60 \%)$ & $270(81 \%)$ & $38,965(60 \%)$ & $<0.001$ \\
\hline Primary kidney disease & & & & $<0.001$ \\
\hline Atheroembolic & & $334(100 \%)$ & & \\
\hline Diabetic nephropathy & & & $21,811(33 \%)$ & \\
\hline Glomerulonephritis & & & $15,879(24 \%)$ & \\
\hline Reflux nephropathy & & & $1890(3 \%)$ & \\
\hline Polycystic disease & & & $3944(6 \%)$ & \\
\hline Hypertension & & & 8339 (13\%) & \\
\hline Other & & & $8866(14 \%)$ & \\
\hline Uncertain & & & $3716(6 \%)$ & \\
\hline Not reported & & & $487(1 \%)$ & \\
\hline Ethnicity & & & & $<0.001$ \\
\hline Caucasian & $45,720(70 \%)$ & $321(96 \%)$ & $45,399(70 \%)$ & \\
\hline All Other & $19,544(30 \%)$ & $13(4 \%)$ & $19,531(30 \%)$ & \\
\hline BMI $\left(\mathrm{kg} / \mathrm{m}^{2}\right)^{\mathrm{a}}$ & & & & $<0.001$ \\
\hline$<18.5$ & $2165(3 \%)$ & $16(5 \%)$ & $2149(3 \%)$ & \\
\hline $18.5-24.9$ & $22,195(35 \%)$ & $174(54 \%)$ & $22,021(35 \%)$ & \\
\hline $25-29.9$ & $19,875(32 \%)$ & $102(31 \%)$ & $19,773(32 \%)$ & \\
\hline$\geq 30$ & $18,702(30 \%)$ & $33(10 \%)$ & $18,669(30 \%)$ & \\
\hline \multicolumn{5}{|l|}{ Comorbidities $^{b}$} \\
\hline Diabetes mellitus & $28,147(44 \%)$ & $76(23 \%)$ & $36,141(56 \%)$ & $<0.001$ \\
\hline$C A D$ & $19,920(31 \%)$ & $265(80 \%)$ & $19,920(31 \%)$ & $<0.001$ \\
\hline PVD & $11,653(18 \%)$ & 195 (59\%) & $11,458(18 \%)$ & $<0.001$ \\
\hline Chronic lung disease & $7986(12 \%)$ & $77(23 \%)$ & $7909(12 \%)$ & $<0.001$ \\
\hline Cerebrovascular disease & $7030(11 \%)$ & $104(32 \%)$ & $6926(11 \%)$ & $<0.001$ \\
\hline Current smoking ${ }^{c}$ & $8532(13 \%)$ & $43(13 \%)$ & 8489 (13\%) & 0.85 \\
\hline Country at cohort entry & & & & $<0.001$ \\
\hline Australia & $53,697(83 \%)$ & $318(95 \%)$ & $53,649(83 \%)$ & \\
\hline New Zealand & $11,299(17 \%)$ & $16(5 \%)$ & $11,283(17 \%)$ & \\
\hline Late referral ${ }^{d}$ & $13,127(21 \%)$ & $154(51 \%)$ & $12,973(21 \%)$ & $<0.001$ \\
\hline Kidney biopsye & $18,903(29 \%)$ & $92(28 \%)$ & $18,811(29 \%)$ & 0.92 \\
\hline \multicolumn{5}{|l|}{ Dialysis Era } \\
\hline 1990-1998 & $13,282(20 \%)$ & $96(29 \%)$ & $13,186(20 \%)$ & $<0.001$ \\
\hline 1999-2007 & $21,521(33 \%)$ & $174(52 \%)$ & $21,347(32 \%)$ & \\
\hline 2008-2017 & $30,463(47 \%)$ & $64(19 \%)$ & $30,399(46 \%)$ & \\
\hline First dialysis modality & & & & $<0.001$ \\
\hline Facility HD & $46,540(71 \%)$ & 275 (82\%) & $46,265(71 \%)$ & \\
\hline PD & $18,441(28 \%)$ & $59(18 \%)$ & $18,382(28 \%)$ & \\
\hline $\mathrm{HHD}$ & $285(0.5 \%)$ & 0 & $285(0.44 \%)$ & \\
\hline
\end{tabular}

Values are expressed as frequency (percentage) for categorical variables, mean \pm standard deviation for normally distributed continuous variables, and median (interquartile range) for non-normally distributed continuous variables

BMI Body Mass Index, CAD Coronary Artery Disease, CVD Composite Cardiovascular Disease; HD Hemodialysis, HHD Home Hemodialysis, KF Kidney Failure, N Number, PD Peritoneal Dialysis, PVD Peripheral Vascular Disease

${ }^{a}$ Data on BMI were missing for $4 \%$ of patients

${ }^{b}$ Data on comorbidities were missing for less than $2 \%$ of patients

c Data on smoking status were missing for $3 \%$ of patients

${ }^{d}$ Data on late referral were missing for $6 \%$ of patients

e Data on Kidney Biopsy were missing for $8.6 \%$ of patients 


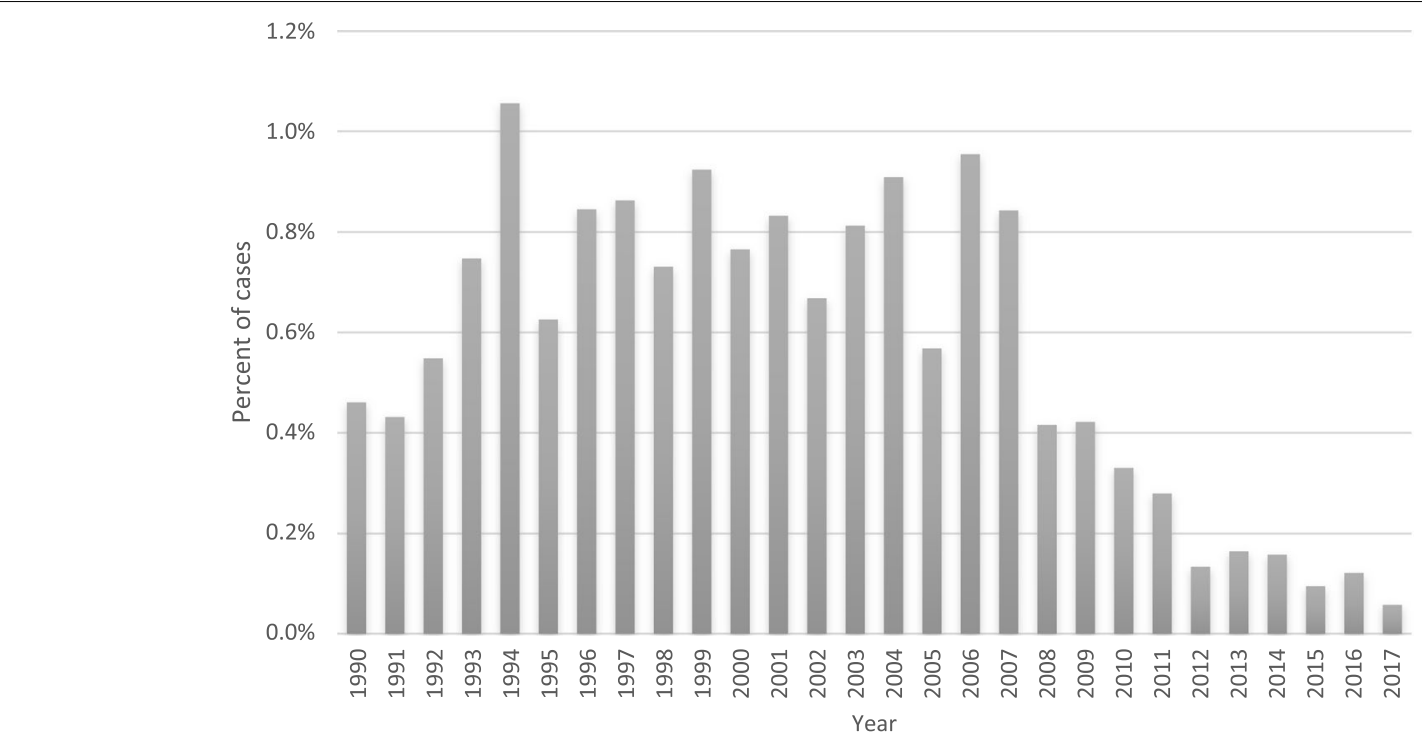

Fig. 2 Annual incidence of kidney failure from atheroembolic disease expressed as a percentage per year of total cases of all kidney failure

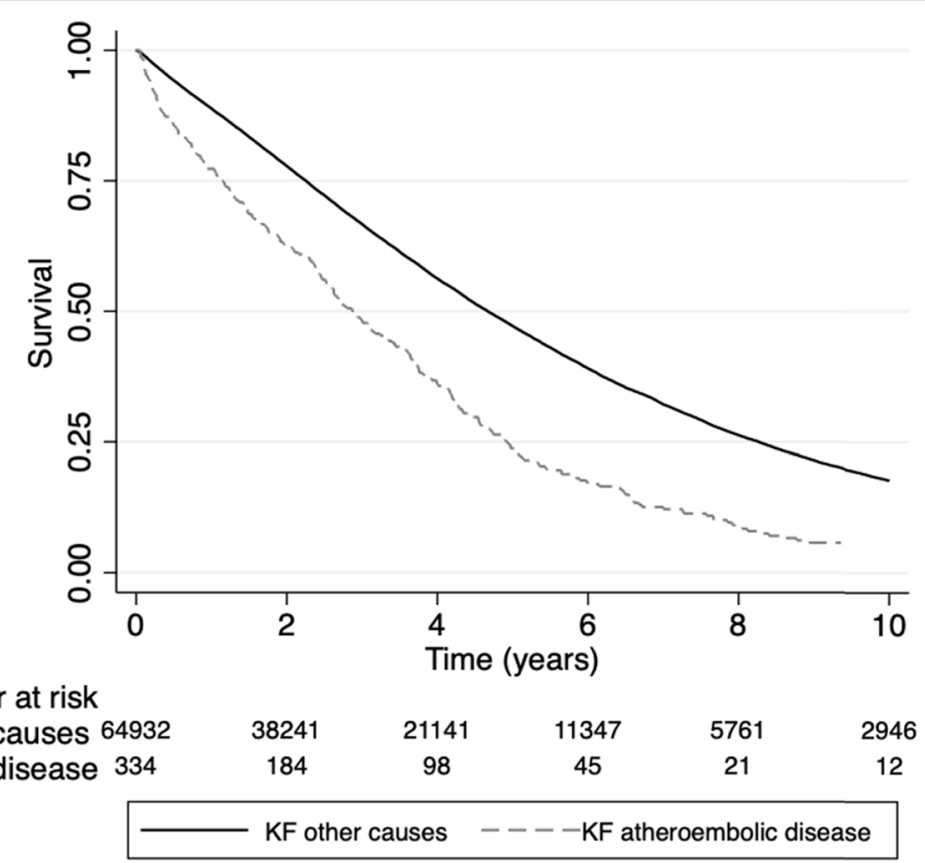

Fig. 3 Survival on dialysis comparing KF from other causes to KF from atheroembolic disease, unadjusted. Dialysis Survival overall log-rank of atheroembolic disease KF vs other KF, $p$-values $<0.001$. KF $=$ Kidney Failure

CI 1.26-1.35) and New Zealand residence (adjusted HR 1.44, 95\% CI 1.39-1.48) (Table 2).

\section{Propensity score matching}

In the propensity score-based 1:3 matched analysis, patient survival was again comparable between patients with KF from atheroembolic disease and other causes $(\mathrm{HR}=1.02,95 \%$ CI $0.89-1.18, p=0.68)$.

\section{Kidney recovery}

There were 31 patients with KF from atheroembolic disease who had kidney function recovery and therefore were independent of dialysis $(n=2[6 \%]<30$ days 
Table 2 Univariable and multivariable Cox proportional hazard model analyses for KF from all other and Atheroembolic KF

\begin{tabular}{|c|c|c|c|c|c|c|}
\hline \multirow[t]{2}{*}{ Characteristics } & \multicolumn{3}{|c|}{ UNIVARIATE } & \multicolumn{3}{|c|}{ MULTIVARIATE } \\
\hline & HR & $95 \% \mathrm{Cl}$ & $p$-value & HR & $95 \% \mathrm{Cl}$ & $p$-value \\
\hline All other KF & Ref & & & Ref & & \\
\hline KF from Atheroembolic Disease & 1.80 & $1.61-2.03$ & $<0.001$ & 0.93 & $0.82-1.05$ & 0.24 \\
\hline Age per decade at cohort entry & 1.41 & $1.40-1.43$ & $<0.001$ & 1.43 & $1.42-1.45$ & $<0.001$ \\
\hline Male sex & 1.04 & $1.01-1.06$ & $<0.001$ & 0.95 & $093-0.97$ & $<0.001$ \\
\hline Primary kidney disease & & & $<0.001$ & & & \\
\hline Diabetic nephropathy & Ref & & & & & \\
\hline Glomerulonephritis & 0.56 & $0.55-0.58$ & $<0.001$ & & & \\
\hline Reflux nephropathy & 0.39 & $0.35-0.42$ & $<0.001$ & & & \\
\hline Polycystic disease & 0.42 & $0.40-0.45$ & $<0.001$ & & & \\
\hline Hypertension & 1.13 & $1.09-1.16$ & $<0.001$ & & & \\
\hline Other & 1.04 & $1.01-1.07$ & $<0.004$ & & & \\
\hline Racial origin & & & $<0.001$ & & & $<0.001$ \\
\hline Caucasian & Ref & & & Ref & & \\
\hline Other & 0.75 & $0.73-0.76$ & $<0.001$ & 0.83 & $0.81-0.85$ & $<0.001$ \\
\hline $\mathrm{BMI}\left(\mathrm{kg} / \mathrm{m}^{2}\right)$ & & & $<0.001$ & & & $<0.001$ \\
\hline$<18.5$ & 1.25 & $1.18-1.32$ & $<0.001$ & 1.43 & $1.35-1.52$ & $<0.001$ \\
\hline $18.5-24.9$ & Ref & & & & & $<0.001$ \\
\hline $25-29.9$ & 0.94 & $0.92-0.97$ & $<0.001$ & 0.88 & $0.86-0.90$ & $<0.001$ \\
\hline$\geq 30$ & 0.84 & $0.82-0.86$ & $<0.001$ & 0.85 & $0.82-0.87$ & $<0.001$ \\
\hline Late referral & 1.17 & $1.14-1.20$ & $<0.001$ & 1.23 & $1.20-1.26$ & $<0.001$ \\
\hline \multicolumn{7}{|l|}{ Comorbidities } \\
\hline Diabetes & 1.38 & $1.35-1.41$ & $<0.001$ & 1.46 & $1.43-1.50$ & $<0.001$ \\
\hline CAD & 1.86 & $1.82-1.90$ & $<0.001$ & 1.30 & $1.28-1.34$ & $<0.001$ \\
\hline PVD & 1.89 & $1.85-1.94$ & $<0.001$ & 1.32 & $1.28-1.35$ & $<0.001$ \\
\hline Chronic lung disease & 1.64 & $1.60-1.69$ & $<0.001$ & 1.30 & $1.26-1.34$ & $<0.001$ \\
\hline Cerebrovascular disease & 1.74 & $1.65-1.75$ & $<0.001$ & 1.20 & $1.17-1.24$ & $<0.001$ \\
\hline Current smoking & 0.97 & $0.94-1.00$ & 0.06 & 1.26 & $1.22-1.30$ & $<0.001$ \\
\hline Dialysis eras (years) & & & $<0.001$ & & & $<0.001$ \\
\hline 1990-1998 & 1.22 & $1.19-1.26$ & $<0.001$ & 1.30 & $1.26-1.35$ & $<0.001$ \\
\hline 1999-2007 & Ref & & & & & \\
\hline 2008-2017 & 0.88 & $0.86-0.90$ & $<0.001$ & 0.85 & $0.83-0.87$ & $<0.001$ \\
\hline Modality & & & $<0.001$ & & & $<0.001$ \\
\hline HD & Ref & & & & & \\
\hline $\mathrm{HHD}$ & 0.22 & $0.14-0.35$ & $<0.001$ & 0.31 & $0.19-0.50$ & $<0.001$ \\
\hline PD & 1.04 & $1.02-1.07$ & $<0.001$ & 1.03 & $1.01-1.06$ & 0.01 \\
\hline \multicolumn{7}{|l|}{ Country } \\
\hline Australia & Ref & & & & & \\
\hline New Zealand & 1.09 & $1.06-1.12$ & $<0.001$ & 1.44 & $1.39-1.48$ & $<0.001$ \\
\hline
\end{tabular}

Multivariable analysis adjusted for: disease group (atheroembolic vs all other KF), age, gender, racial origin (Caucasian vs other), sub-era, kidney replacement modality, late referral, current smoking, body mass index, comorbidities at entry (diabetes mellitus, coronary artery disease, peripheral vascular disease, chronic lung disease and cerebrovascular disease) and country (Australia vs New Zealand)

95\% Cl 95\% confidence interval, BMI Body Mass Index, CAD Coronary Artery Disease, CVD Composite Cardiovascular Disease, HD Hemodialysis, HHD Home Hemodialysis, HR Hazard Ratio, N Number, PD Peritoneal Dialysis, PVD Peripheral Vascular Disease, Ref Reference

on dialysis and $n=29$ [94\%] after >90 days on dialysis) versus 1368 patients with KF from other causes ( $n=190[14 \%]<30$ days from dialysis, $n=314$ [23\%] after 30-90 days on dialysis and $n=864$ [63\%] after $>90$ days on dialysis, Table 3).

\section{Transplant}

Patients with KF from atheroembolic disease were significantly less likely to receive a kidney transplant $(n=5)$ throughout the study period compared to those with other causes of KF $(n=15,044 ; 1.5 \%$ vs $23 \%, P=0.001)$. 
Table 3 End of study event outcomes

\begin{tabular}{llll}
\hline & All & $\begin{array}{l}\text { KF from } \\
\text { atheroembolic } \\
\text { disease }\end{array}$ & KF all other causes \\
\hline $\mathbf{n =}$ & $\mathbf{6 5 , 2 6 6}$ & $\mathbf{3 3 4}$ & $\mathbf{6 4 , 9 3 2}$ \\
$\begin{array}{l}\text { Death on dialysis } \\
\text { Total kidney recovery }\end{array}$ & $\mathbf{3 4 , 5 7 1}$ & $283(84.7 \%)$ & $34,288(52.8 \%)$ \\
$\begin{array}{l}\text { Kidney recov- } \\
\text { ery<30 days }\end{array}$ & & $21(9.3 \%)$ & $1368(2.1 \%)$ \\
$\begin{array}{l}\text { Kidney recovery } \\
\text { 30-89days }\end{array}$ & & 0 & $190(14 \%)$ \\
$\begin{array}{l}\text { Kidney recov- } \\
\text { ery }>90 \text { days }\end{array}$ & & $29(93.5 \%)$ & $864(63.2 \%)$ \\
$\begin{array}{l}\text { Transplant } \\
\text { Loss to follow up }\end{array}$ & 15,049 & $5(1.5 \%)$ & $15,044(23 \%)$ \\
End of study & 14,123 & 0 & $124(19 \%)$ \\
\hline
\end{tabular}

KF Kidney failure

\section{Discussion}

This is the largest multicenter study to date comparing dialysis survival outcomes of KF from atheroembolic disease to all other causes of KF. It showed those with KF from atheroembolic disease were less likely to survive on dialysis, with the lead cause of death being cardiovascular disease followed by dialysis withdrawal. However, after adjustment for demographic factors and comorbidities, those with KF from atheroembolic disease no longer had lower survival on dialysis, suggesting that the accompanying risk factors for atheroembolic kidney disease predisposed to death rather than the disease itself. In this study, those with KF from atheroembolic disease were more likely to become independent from dialysis after a longer duration on KRT of more than 90 days and had a lower rate of transplantation in comparison to all other KF.

We observed a 1-year survival rate of $77 \%$ in patients with KF from atheroembolic disease, which appears to be comparable to that of previous studies of $82-87 \%$ $[6,7]$. The median survival of 2.87 years was worse than the findings of a single centre observational study which reported a median survival of 4.08 years. Besides the smaller cohort size of 95 patients, the other main disparity between this cohort study and our study that may explain our inferior survival rate was a lower rate of diabetes mellitus of $15 \%$ (versus $23 \%$ ) and their cohort was mostly patients acutely initiated on dialysis, of whom only $24 \%$ remained on maintenance dialysis [6]. Lastly, the above two studies only reviewed outcomes in Atheroembolic KF and did not compare to other causes of KF. Cardiovascular disease was the leading cause of death in our study, similar to other reports [3]. This is unsurprising given the atherosclerotic background of this population.
Although KF due to atheroembolic disease was associated with higher mortality in univariable Cox regression compared to other causes of KF, this association was no longer significant after adjustment for other patient characteristics. In multivariable Cox regression models, older age, late referral to nephrologist care, diabetes mellitus, coronary artery disease, peripheral vascular disease, chronic lung disease, cerebrovascular disease, current smoking, peritoneal dialysis, the dialysis era 1990-1998 and being from New Zealand were associated with significantly higher mortality. Aggressive management of predisposing comorbidities and earlier referral to nephrology care could represent potential target areas for management in this population. However, it could be postulated that the higher mortality associated with late referral might be related to the indication for angiography leading to atheroembolic disease, independent of kidney function. Furthermore, a late referral is inevitable in many cases of KF due to atheroembolic disease, given that it is iatrogenic in greater than $75 \%$ of cases in the setting of unavoidable interventions, frequently in those with pre-existing CKD [10].

In this study, atheroembolic disease represented $0.5 \%$ of all causes of KF in patients initiating dialysis in Australia and New Zealand between 1990 and 2017. This is consistent with previous studies reporting a prevalence of atheroembolic disease on kidney biopsies around $1 \%[7,8]$. An interesting trend identified in the present study was that the annual incidence of cases of KF from atheroembolic disease has fallen since 2008, with an overall lower incidence of cases in the dialysis era of 2008-2017 (19\%) versus other eras (1990-1998, 29\% \& 1999-2007, 52\%). We hypothesize that this observation was related to a temporal change in Australian cardiology practice with higher uptake of the radial approach versus femoral approach for coronary angiography across this period [11]. This practice change is supported by the National Heart Foundation guidelines recommending the radial approach as the preferred access for percutaneous intervention [12]. Femoral intra-arterial access is associated with higher rates of acute kidney injury compared with the radial approach [2] and presumably therefore also with more atheroembolic disease, documented to cause up to $78 \%$ of atheroembolic kidney disease [9], due to the catheter traversing the abdominal aorta dislodging atherosclerotic plaque into the renal arteries [10]. Another potential explanation for the declining incidence seen in our study is a growing tendency by nephrologists towards offering conservative care rather than dialysis to patients who are older and more co-morbid, with ANZDATA only capturing patients who start KRT. There has been a steady growth of dedicated kidney 
supportive care services in nephrology units across Australia and New Zealand [13], although the referral patterns and clinical uptake of these services have not been directly studied. Lastly, KF from atheroembolic disease may also be relatively under-diagnosed and under-reported in patients with other CKD risk factors, such as diabetes and hypertension, who are less likely to undergo kidney biopsy, as exemplified by a low overall biopsy rate of $29 \%$ within our study.

There was minimal kidney function recovery for patients with KF attributable to atheroembolic disease in our study, in contrast to other studies reporting rates of recovery and freedom off dialysis ranging from 21 to $39 \%$ [3]. This result may be explained by the structure of ANZDATA registry which only enrolls patients anticipating chronic dialysis and does not include patients with acute but temporary kidney failure. Despite the low recovery rate, those with $\mathrm{KF}$ from atheroembolic disease were more likely than patients with other aetiologies to have kidney function recovery after a dialysis duration of 90 days or more. A proposed mechanism could be stabilization of aortic cholesterol plaques and continued regression of embolized crystals after the precipitating event and ostensible commencement of statin therapy. Statin therapy is known to stabilise and regress cholesterol plaques and has been documented to improve kidney outcomes in atheroembolic disease [6, 14].

Overall, there were low rates of transplantation, with no pre-emptive kidney transplants for those with $\mathrm{KF}$ from atheroembolic disease. The small number of kidney transplantations prevented meaningful analysis of outcomes in comparison to other causes of KF undergoing transplantation. The low transplantation rate is plausibly related to the patient's profiles observed in our study, with those with KF from atheroembolic disease being older Caucasian men with comorbidities such as coronary artery disease, peripheral vascular disease, chronic lung disease and cerebrovascular disease. This older population with a risk profile would typically be considered ineligible or unfavourable for transplantation. This is further exemplified by the observed low uptake of home therapies within the cohort. To our knowledge, this is the first study within the literature that has looked at transplantation and home therapies uptake in KF from atheroembolic disease.

The strengths of our study were the large sample size ( $n=65,266$ ), long follow-up duration (total 225,432 patient-years), sufficient event numbers to enable assessment of mortality and comprehensive capture of data on all patients starting KRT in Australia and New Zealand. One of the limitations of the study was that
ANZDATA registry does not collect information on those with stage 5 CKD who elected to receive conservative care rather than KRT, such that the absence of this information would reduce the overall number of analysed cases and may have led to ascertainment bias if the uptake of KRT differed between atheroembolic kidney disease and other forms of KF. Furthermore, there was a limited depth of data collection, such that the possibility of residual confounding could not be excluded. There was also the potential for coding bias with respect to nephrologists and their diagnoses of KF from atheroembolic disease.

In conclusion, this study demonstrates that patients with KF from atheroembolic disease have a higher mortality rate on dialysis in comparison to those with KF from other aetiologies, which was no longer observed after adjustments for patient demographic characteristics and comorbidities. It also demonstrates a temporal trend in the reduction of the annual incidence of KF from atheroembolic disease. Further research is warranted to determine whether this temporal trend reflects changes in angiographic practices, changes in vascular disease prevalence or other factors.

\section{Acknowledgements \\ NA. \\ Authors' contributions \\ All authors worked on the design of the study. TS analysed the data, made the figures and drafted the paper. IE, CH, EMP, AN, AV, YC and DWJ provided guidance on data analysis and interpretation. EMP provided statistical advice. All authors revised the paper. The author(s) read and approved the final manuscript.}

\section{Funding}

$\mathrm{CH}$ reports personal fees from GlaxoSmithKline and grant support from Baxter, Fresenius and NHMRC, outside the submitted work. AV reports funds from Jacquot Research Establishment Fellowship. YC reports personal fees from Baxter, and grant support from Fresenius Medical Care, NHMRC and Baxter CEC Grant, outside the submitted work. DJ reports personal fees from AWAK, Astra-Zeneca, Baxter Healthcare and Fresenius Medical Care, travel sponsorship from ONO and Amgen and grant support from Baxter Extramural Grant and Baxter CEC Grant and NHMRC, outside the submitted work.

\section{Availability of data and materials}

The dataset analysed during the study is available through the ANZDATA registry and can be requested by completing a data request and emailing requests@anzdata.org.au.

\section{Declarations}

\section{Ethics approval and consent to participate}

Ethics was received from Princess Alexandra Hospital Human Research Ethics Committee (LNR/2019/QMS/50454). The Authors confirm that all methods were carried out in accordance with relevant guidelines and regulations. We confirm that all experimental protocols were approved by a named institutional and/or licensing committee. Consent for publication was not applicable as the data used from ANZDATA was de-identified. The Princess Alexandra Hospital Human Research Ethics Committee reviewed the research protocol and gave formal approval for consent wavier. 


\section{Consent for publication}

Consent for publication was not applicable.

\section{Competing interests}

The authors declare that they have no competing interests.

\section{Author details}

'Department of Nephrology, Level 2, ARTS Building, Princess Alexandra Hospital, 199 Ipswich Road, Woolloongabba, Brisbane, QLD 4102, Australia. ${ }^{2}$ School of Medicine, University of Queensland, Brisbane, Australia. ${ }^{3}$ Division of Nephrology, Centre Hospitalier de l'Université de Montréal, Montréal, Canada. ${ }^{4}$ Australia and New Zealand Dialysis and Transplant (ANZDATA) Registry, Adelaide, Australia. ${ }^{5}$ Australasian Kidney Trials Network, University of Queensland, Brisbane, Australia. ${ }^{6}$ Translational Research Institute, Brisbane, Australia.

${ }^{7}$ Department of Cardiology, Princess Alexandra Hospital, Brisbane, Australia.

Received: 3 May 2021 Accepted: 3 November 2021

Published online: 02 December 2021

\section{References}

1. Saran R, Robinson B, Abbott KC, Agodoa LYC, Albertus P, Ayanian J, et al. US renal data system 2016 annual data report: epidemiology of kidney disease in the United States. Am J Kidney Dis. 2017;69(3):A7-8.

2. Vuurmans T, Byrne J, Fretz E, Janssen C, Hilton JD, Klinke WP, et al. Chronic kidney injury in patients after cardiac catheterisation or percutaneous coronary intervention: a comparison of radial and femoral approaches (from the British Columbia cardiac and renal registries). Heart. 2010;96(19):1538-42.

3. Scolari F, Ravani P. Atheroembolic renal disease. Lancet. 2010;375(9726):1650-60.

4. Jones DB, lannaccone PM. Atheromatous emboli in renal biopsies. An ultrastructural study. Am J Pathol. 1975;78(2):261-76.

5. Preston RA, Stemmer CL, Materson BJ, Perez-Stable E, Pardo V. Renal biopsy in patients 65 years of age or older an analysis of the results of 334 biopsies. J Am Geriatr Soc. 1990;38(6):669-74.

6. Scolari F, Ravani P, Pola A, Guerini S, Zubani R, Movilli E, et al. Predictors of renal and patient outcomes in Atheroembolic renal disease: a prospective study. J Am Soc Nephrol. 2003;14(6):1584-90.

7. Belenfant $X$, Meyrier A, Jacquot C. Supportive treatment improves survival in multivisceral cholesterol crystal embolism. Am J Kidney Dis. 1999;33(5):840-50.

8. Fine MJ, Kapoor W, Falanga V. Cholesterol crystal embolization: a review of 221 cases in the English literature. Angiology. 1987;38(10):769-84.

9. von Elm E, Altman DG, Egger M, Pocock SJ, Gøtzsche PC, Vandenbroucke $J$, et al. The strengthening the reporting of observational studies in epidemiology (STROBE) statement: guidelines for reporting observational studies. Bull World Health Organ. 2007;85(11):867-72.

10. Scolari F, Ravani P, Gaggi R, Santostefano M, Rollino C, Stabellini N, et al. The challenge of diagnosing Atheroembolic renal disease. Circulation. 2007;116(3):298-304.

11. Ocsan RJ, Doost A, Marley P, Farshid A. The rise of transradial artery access for percutaneous coronary intervention in patients with acute coronary syndromes in Australia. J Interv Cardiol. 2020;2020:4397697.

12. Chew DP, Scott IA, Cullen L, French JK, Briffa TG, Tideman PA, et al. National Heart Foundation of Australia \& Cardiac Society of Australia and New Zealand: Australian Clinical Guidelines for the Management of Acute Coronary Syndromes 2016. Heart Lung Circ. 2016;25(9):895-951.

13. Ducharlet K, Philip J, Kiburg K, Gock H. Renal supportive care, palliative care and end-of-life care: perceptions of similarities, differences and challenges across Australia and New Zealand. Nephrology. 2021;26(1):15-22.

14. Woolfson RG, Lachmann $\mathrm{H}$. Improvement in renal cholesterol emboli syndrome after simvastatin. Lancet. 1998;351(9112):1331-2.

\section{Publisher's Note}

Springer Nature remains neutral with regard to jurisdictional claims in published maps and institutional affiliations.

Ready to submit your research? Choose BMC and benefit from:

- fast, convenient online submission

- thorough peer review by experienced researchers in your field

- rapid publication on acceptance

- support for research data, including large and complex data types

- gold Open Access which fosters wider collaboration and increased citations

- maximum visibility for your research: over $100 \mathrm{M}$ website views per year

At BMC, research is always in progress.

Learn more biomedcentral.com/submissions 